\section{Relationships between protein and mineral during enamel development in normal and genetically altered mice}

\author{
Smith CE, Hu Y, Richardson AS, Bartlett JD, Hu JC-C, Simmer JP. Relationships \\ between protein and mineral during enamel development in normal and genetically altered \\ mice. \\ Eur J Oral Sci 2011; 119 (Suppl. 1): 125-135. (C) 2011 Eur J Oral Sci
}

The purpose of this study was to quantify and compare the amounts of volatiles (mostly protein) and mineral present in developing incisor enamel in normal mice and in those genetically engineered for absence of intact enamelin, ameloblastin, matrix metalloproteinase 20 (MMP20) or kallikrein-related peptidase 4 (KLK4). Data indicated that all mice showed peaks in the gross weight of volatiles and a similar weight of mineral at locations on incisors normally associated with early maturation. Thereafter, the content of volatiles on normal incisors declined rapidly by as much as $62 \%$, but not by $100 \%$, over $2 \mathrm{~mm}$, accompanied by increases of $\sim$ threefold in mineral weights. Enamelin heterozygous mice (lower incisors) showed a decrease in volatile content across the maturation stage, yet mineral failed to increase significantly. Mmp20 null mice showed no significant loss of volatiles from maturing enamel, yet the amount of mineral increased. Klk4 null mice showed normal mineral acquisition up to early maturation, but the input of new volatiles in mid to late maturation caused the final mineralization to slow below normal levels. These results suggest that it is not only the amount of protein but also the nature or type of protein or fragments present in the local crystallite environment that affects their volumetric expansion as they mature.

\section{Charles E. Smith ${ }^{1,2}$, Yuanyuan $\mathrm{Hu}^{2}$, Amelia S. Richardson ${ }^{2}$, John D. Bartlett ${ }^{3}$, Jan C-C. $\mathrm{Hu}^{2}$, James P. Simmer ${ }^{2}$}

${ }^{1}$ Facility for Electron Microscopy Research, Department of Anatomy \& Cell Biology, and Faculty of Dentistry, McGill University, Montreal, QC, Canada; ${ }^{2}$ Dental Research Laboratory, Department of Biologic and Materials Sciences, School of Dentistry, University of Michigan, Ann Arbor, MI, USA; ${ }^{3}$ Department of Cytokine Biology, Forsyth Institute and Department of Developmental Biology, Harvard School of Dental Medicine, Cambridge, MA, USA

Charles E. Smith. Department of Anatomy \& Cell Biology, McGill University, 3640 University Street, Montreal, QC, Canada H3A 2B2

\section{Telefax: +1-514-3985047}

E-mail: charles.smith@mcgill.ca

Key words: ameloblastin; enamelin; KLK4; mineral; matrix metalloproteinase 20 (MMP20)

Accepted for publication July 2011
One factor that seems to exert major control over enamel development is the matrix proteins that help to promote and stabilize initial deposits of mineral as the enamel layer thickens by appositional growth (1). However, these same proteins and/or their fragments unless removed are believed capable of 'poisoning' the secondary mineralization process that is associated with volumetric growth of apatite crystallites later during the maturation stage of amelogenesis (2-4). This notion is based largely on findings that (i) the degradation and seemingly total removal of enamel matrix proteins (amelogenin, enamelin, and ameloblastin) normally occurs before the crystallites start undergoing their rapid volumetric expansion (2); and (ii) excess amounts of residual enamel matrix proteins/fragments, in some cases supplemented with serum proteins such as albumin, are usually detected at sites where hypomineralization defects occur in the enamel $(2,5)$. Undermineralized enamel typically appears chalky and white, and the affected areas abrade easily when these teeth erupt into occlusion. This can have disastrous consequences in cases of genetic mutations where the entire crowns of teeth are covered with poor-quality enamel. This substantially reduces the functional longevity of the affected dentition.

The exact method(s)/pathway(s) by which matrix proteins are removed from maturing enamel in vivo are presently only partially defined (4). This is understand- able considering the unique nature of such an event within the context of the way in which mineralization normally occurs in all other mammalian hard tissues. In bone and dentin, for example, the formative cells (osteoblasts and odontoblasts) intentionally create a delay between the time when matrix proteins are secreted and the time when mineral is deposited in association with them. This delay, as osteoid and predentin, is necessary to allow tropocollagen molecules, secreted by the cells, to aggregate into fibrils and cross-link themselves for stability (6). It is only once the fibrils have reached an optimal size and become spatially organized, in some cases into very complex lamellar patterns, that specific non-collagenous components and mineral are added onto the fibrils (7). The numerous, small, plate-like crystallites of hydroxyapatite appearing along the mineralizing front in these hard tissues do not change much in size thereafter, and the supporting scaffold of collagen fibrils does not change unless resorbed by osteoclasts/ odontoclasts.

In contrast, the main matrix protein in developing enamel, amelogenin, is globular in nature and has a propensity to self-aggregate/assemble at the submicroscopic/nanoscale level into spheres, ovals, and/or ribbons $(1,8,9)$ rather than to form rigid cross-linked fibrils as occurs in the collagen-based hard tissues. Forming and mature enamel show considerable structural complexity 
in terms of rod and inter-rod organizations, as viewed by both light and electron microscopy (4), but this complexity results from the complicated three-dimensional (3D) arrangements of constituent and highly elongated hydroxyapatite crystallites, rather than from the organic matrix itself where constituent proteins start degrading incrementally within minutes or hours from when they are secreted (10). These may be among the reasons why enamel does not linger for any length of time as an unmineralized pre-enamel, but instead has mineral deposited simultaneously with exocytosis of matrix proteins from the ameloblasts (11). The lack of structural complexity and rigidity within the organic framework of enamel is also probably an attribute that makes enamel matrix proteins accessible and easier to break down and remove from the enamel layer during development.

Current evidence suggests that at least two pathways are utilized to remove proteins from the enamel layer during development. One involves the sequential secretion of two proteinases possessing vastly different properties and cleavage-site specificities $(12,13)$. The first proteinase to appear in enamel development is matrix metalloproteinase 20 (MMP20) which is released extracellularly along with amelogenin, enamelin, and ameloblastin as the enamel layer thickens by appositional growth during the secretory stage $(14,15)$. Matrix metalloproteinase 20 serves an important function to initiate certain key hydrolytic cleavages on the enamel matrix proteins within minutes or hours of their secretion. This results in the formation of variably sized protein fragments that gradually become the primary organic component in the extracellular milieu as development proceeds (4). There is increasing evidence that these fragments have physical properties which are different from their original secretory forms, and that the fragments, which in many cases show distinct distribution patterns within the enamel layer, may serve functions that are different from their intact parental forms $(2,4$, 16-18). Ameloblasts switch their emphasis from producing MMP20 to expressing and secreting the second, more active, proteinase called kallikrein-related peptidase 4 (KLK4) as they undergo postsecretory transition into maturation (19-21). This hydrolase is active throughout the maturation stage and appears to further degrade fragments of amelogenin, enamelin, and ameloblastin so they can be removed and thus provide the space needed for the volumetric expansion of crystallites seeded and lengthened in the secretory stage (22).

The second pathway that is suspected to be important for the removal of proteins/fragments from the enamel layer is based on a currently ill-defined biological process called 'resorptive activity of ameloblasts' (4, 23-26). In this process, organic material within the enamel layer flows in a direction towards the enamel organ and comes into contact with the apical surfaces of ameloblasts that lie against and cover the enamel surface (4). From here, the residual organic material is taken up into endocytotic vesicles and transferred to the lysosomal system of ameloblasts for final degradation (4, 27). There has never been much direct evidence for such a garbage-disposal mechanism operating during the maturation stage, but it is clear that modulating maturation-stage ameloblasts contain numerous vacuoles and dense bodies suggestive of high endocytotic activity (28$31)$. These cells are also capable of moving peroxidase and other fluid-phase tracers from the cell surface into lysosomes $(29,30,32)$. Additionally, enamel will remain undermineralized and infused with higher-than-normal amounts of residual protein if the enamel organ cells are damaged or removed shortly after the maturation stage begins (33).

The purpose of this study was to gain insight into the relationships between the quantity of mineral and protein that co-exist as the enamel forms and matures. In particular, we were most interested in defining the time in amelogenesis when the maximum amounts of matrix proteins are present within the enamel layer and the quantity of mineral associated with the proteins at this time. We also wanted to determine the amount of proteins lost up to the point where the enamel accumulates enough mineral to render it physically hardened. Another goal was to look at what happens to mineral and bulk protein content when there is loss of function of either one of the two non-amelogenins (enamelin and ameloblastin), believed to be important for mineral induction and cell adhesion, or of either one of the two secreted enamel proteinases (MMP20 and KLK4) that are known to be responsible for postsecretory processing and degradation of enamel matrix proteins.

\section{Material and methods}

The data presented in this study on mineral and protein contents at various time-points during enamel development derive from two investigations reported previously $(34,35)$ that were focused on defining the major effects resulting from the loss of function of enamelin (36), ameloblastin (37), MMP20 (38), and KLK4 (39). The tables and graphs included in this study are all new and were not presented previously. Previously published papers $(34,35)$ should be consulted for details on (i) genetic alterations made to create loss of function of specific enamel matrix proteins or proteinases, (ii) animal breeding, handling, preparation, and adherence to governmental guidelines regarding humane treatment, (iii) the processing of incisors, (iv) the preparation of 1-mm-long strips of freeze-dried enamel and their subsequent weighing, heating (ashing) for $18 \mathrm{~h}$ at $575^{\circ} \mathrm{C}$, and reweighing, and (v) the methods for statistical analyses of data. It should be noted that the loss-of-function mouse models examined here for enamelin (36) and KLK4 (39) are true null conditions, in which the respective gene was deleted and replaced with a bacterial lac $Z$ nuclear reporter gene. The MMP20 loss-of-function mouse model is based on the replacement of part of intron 4 and all of exon 5 with a minigene that eliminates the catalytic activity of MMP20 (38). Western blot analyses of secretory-stage enamel extracts are completely negative for MMP20, suggesting that no truncated form of MMP20 is expressed (40). The ameloblastin loss-of-function mouse model is an engineered mutant (37). Ameloblasts in these mice secrete a version of ameloblastin, but it is shorter by 117 amino-acid residues because exons 5 and 6 have been deleted $(37,41)$. The contributions of this truncated protein to the effects observed on enamel formation in the mutant mice are unknown. 


\section{Histology}

All procedures involving mice were reviewed and approved by the Institutional Animal Care and Use Committees (IACUC) of the University of Michigan. Seven-week-old mice with the desired genotype (wild type, Enam ${ }^{-1-}$, $\mathrm{Mmp} 2 \mathrm{O}^{-/-}$or $\mathrm{Klk}^{-/-}$) were anesthetized with isoflurane and fixed by cardiac perfusion. Blood was cleared from the vasculature using lactated Ringer's solution (30-45 s) followed by $2.5 \%$ glutaraldehyde in $0.08 \mathrm{~m}$ sodium cacodylate buffer containing $0.05 \%$ calcium chloride, $\mathrm{pH} 7.3$, for 20 min. The jaws were removed, cleaned of skin, adhering muscle, and soft tissues, and immersed in fresh fixative for $2-3 \mathrm{~h}$ at $4^{\circ} \mathrm{C}$. The jaws were washed for $30-60 \mathrm{~min}$ in four or five changes of cold $0.1 \mathrm{M}$ sodium cacodylate buffer, $\mathrm{pH}$ 7.4 , containing $4 \%$ sucrose. They were then put in gauze biopsy bags or plastic cassettes and suspended for 3-4 wk at $4{ }^{\circ} \mathrm{C}$ with agitation in $4.13 \%$ disodium EDTA. The jaws were washed for $2 \mathrm{~d}$ in frequent changes of cacodylate-sucrose buffer, postfixed for $2 \mathrm{~h}$ in reduced osmium tetroxide (equal parts of $3 \%$ potassium ferrocyanide and $2 \%$ osmium tetroxide), dehydrated in acetone, and infiltrated and embedded in Epon 812 substitute. Transverse (cross) sections of mandibular incisors were cut at $0.5-\mu \mathrm{m}$ thickness with a HistoKnife (Diatome USA, Hatfield, PA, USA) at selected sites along the length of the tooth, transferred to glass slides and stained with $0.1 \%$ toluidine blue. Digital imaging was performed on a Zeiss Axioskop 2 mot microscope (Carl Zeiss Canada, Montreal, QC, Canada) using a Zeiss HR color camera and Zeiss AxioVision v4.7 software.

\section{Results}

Reliability of microweighing, changes to hydroxyapatite resulting from heating at $575^{\circ} \mathrm{C}$, and accuracy of estimating the protein content in enamel samples by deductive microweighing

Dissections of 1-mm-long enamel strips from mouse incisors (Fig. 1) are time consuming, can take longer than 1 month to complete per genotype, and require the precise measurement of small samples. This raises questions about how accurately a microbalance can weigh the same object over long periods of time, especially across different seasons where humidity and temperature changes can be extreme. Weight measurements made over a period of 14 months for the same small aluminum pan of the type used for weighing enamel strips varied by only $\pm 0.2 \mu \mathrm{g}$. The absolute range of measurements over 14 months was $0.6 \mu \mathrm{g}$. For these reasons, weight measurements of enamel strips below $1 \mu \mathrm{g}$ are considered unreliable.

Table S1 shows differences between the weights, before and after ashing (heating at $575^{\circ} \mathrm{C}$ ), of various samples of hydroxyapatite, octacalcium phosphate, and calcium carbonate. As indicated, some loss in mass was detected for all mineral samples as a result of the release of water vapor and/or carbon dioxide gas through heating (42). The greatest weight changes were observed with octacalcium phosphate (which is rich in heat-labile acid phosphates) and with calcium carbonate (Table S1). The various hydroxyapatite samples tested showed a range of weight losses varying from $0.04 \%$ for ceramic grade
LOCATION OF STAGES OF AMELOGENESIS ON MOUSE INCISORS
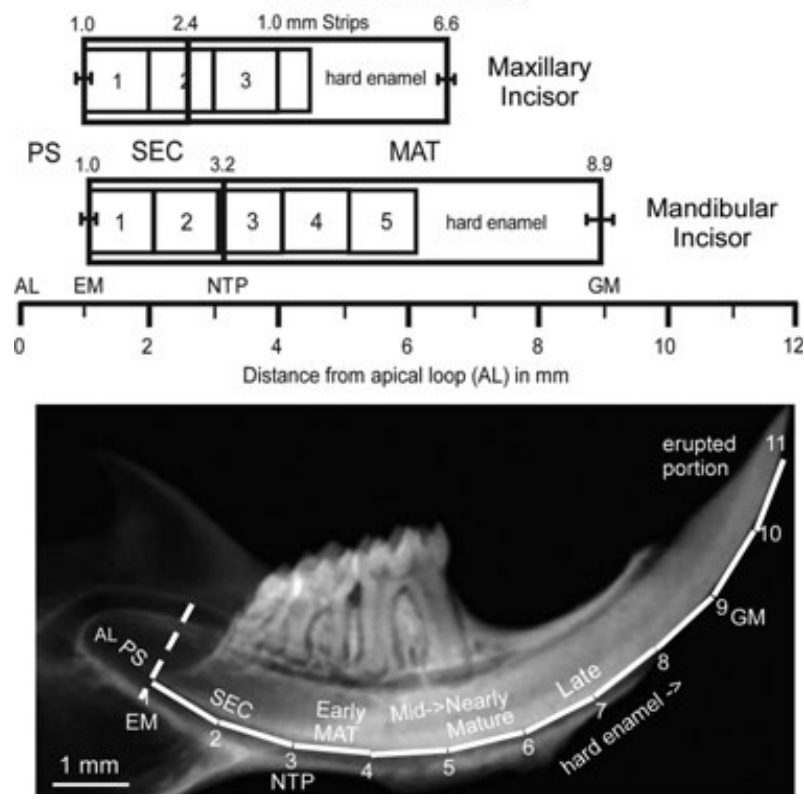

Fig. 1. Schematic drawing of the location of stages of amelogenesis and sites for enamel strip dissections on maxillary and mandibular mouse incisors, and radiograph of a mandibular incisor enlarged to a similar scale as the schematic drawing. In normal wild-type mice, three, and sometimes four, 1-mm-long strips of developing enamel can generally be dissected from maxillary incisors across the length of the tooth from the start of the secretory stage (EM, SEC) to about the midpoint of the maturation stage (MAT), where the enamel becomes so hard that it physically damages the scalpel blades used to partition the enamel layer into strips. On mandibular incisors, usually two strips can be obtained from the secretory stage and three strips from the maturation stage before the enamel is too hard to dissect by hand. Because the average strip number per series is not an integer on maxillary incisors (3.5 strips per series per tooth) unlike mandibular incisors (5.0 strips per series per tooth), data for the most incisally positioned strip on maxillary incisors tend to have higher variation than comparable strips on mandibular incisors. In the radiograph below the schematic drawing, the dotted line indicates the boundary between the presecretory stage (PS) and the beginning of the secretory stage (SEC) on the mandibular incisor. The numbered white lines correspond to imaginary strips spaced at $1-\mathrm{mm}$ intervals. AL, apical loop; EM, the point marking the start of enamel matrix formation; GM, gingival margin where the erupted portion of the incisor starts; MAT, maturation stage; NTP, 'no Tome's processes' visible on ameloblasts; PS, presecretory stage.

hydroxyapatite (which has large, fused crystals) to $4.95 \%$ for a sample that has small hydroxyapatite crystal sizes (Monsanto, $59.6 \mathrm{~m}^{2} \mathrm{~g}^{-1}$ specific surface area) (Table S1). As the trend in enamel formation is for hydroxyapatite crystals to increase in size and crystallinity with development, these data suggest that some of the weight loss detected in freeze-dried enamel strips after heating at $575^{\circ} \mathrm{C}$ could arise from 'burning off' volatile components associated with the mineral phase (43), but this would probably comprise no more than a maximum of $\sim 5 \%$ of the total weight loss and would be more of a potential problem for strips taken from the secretory and earlymaturation stages where crystals sizes are the smallest. 
Figure S1 shows estimated amounts of protein contained within 1-mm-long freeze-dried enamel strips removed from incisors. These results were obtained using the Lowry protein assay with BSA and recombinant mouse amelogenin (rM179) as standaras for estimating protein concentrations. Superimposed on the Lowry estimates are the results for the amount of volatiles contained in enamel strips, as determined by deductive weighing on the microbalance (volatile weight $=$ starting dry weight - weight after ashing). As indicated, protein estimates for enamel strips based on rM179 are almost identical to the estimates of volatile content in enamel strips taken from the secretory- and early-maturation stages (Fig. S1, red and green), whereas protein estimates based on BSA (Fig. S1, blue) provide a closer match to volatile content for mid- to late-maturation stages, except for the most mature enamel strip that seems to contain a source of volatiles other than protein (Fig. S1, strip 11; green symbol significantly higher than the red or the blue symbol at $P<0.05$ ). These results suggest that in most cases the word "volatiles' is synonymous with 'protein' for the purposes of this study.

\section{Mineral and volatile content in enamel on maxillary and mandibular incisors of wild-type mice}

It was possible to cut three, 1-mm-long strips on maxillary incisors and five, 1-mm-long strips on mandibular incisors before the enamel was so hard that it damaged the scalpel blade used to make mesial-to-lateral releasing cuts across the labial surface (Fig. 1, orientation; Figs 2 $\mathrm{A}, \mathrm{C}$ and $3 \mathrm{~A}, \mathrm{C}$; blue and red symbols). A peak at 21$25 \mu \mathrm{g} \mathrm{mm}^{-1}$ in volatile contents was generally detected in the second strip on maxillary incisors and a peak at 26$33 \mu \mathrm{g} \mathrm{mm}^{-1}$ was detected in the third strip on mandibular incisors (early maturation, Fig. 1; Table S2, +/+; Figs 2A,C and 3A,C; red symbols; Fig. 4, blue symbols). Generally, these strips at this time contained $17 \mu \mathrm{g} \mathrm{mm}^{-1}$ of mineral on maxillary incisors and $34 \mu \mathrm{g} \mathrm{mm}-1$ of mineral on mandibular incisors, representing $43 \%$ and $53 \%$ mineral by dry weight, respectively (Table S2, +/ + ; Figs 2A,C and 3A,C; blue symbols; Fig. 5, blue symbols). The volatile content in the strips then decreased sharply while the mineral content rose dramatically between strips 2 and 3 on maxillary incisors and between strips 3 and 4 , and sometimes strip 5, on
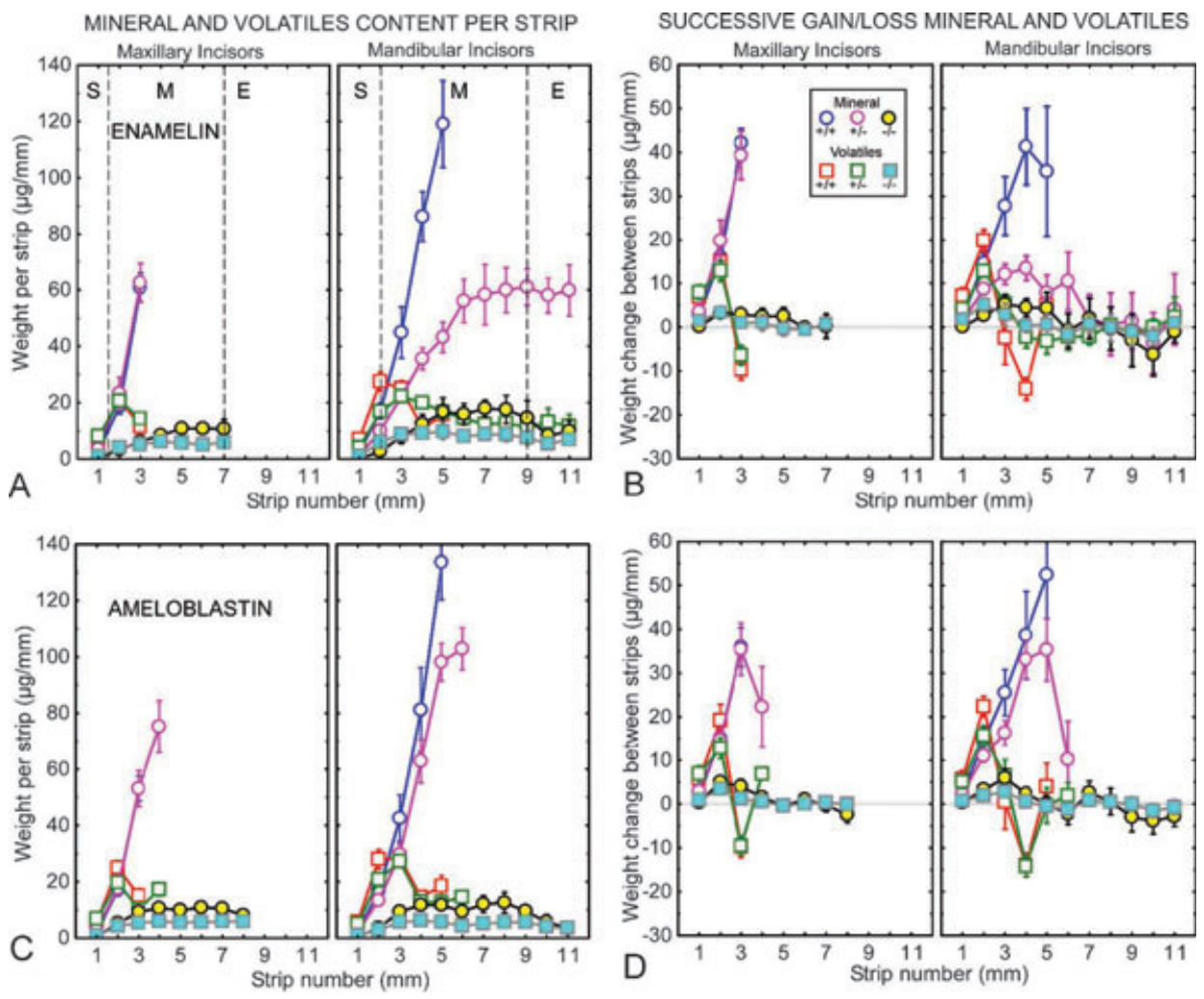

Fig. 2. Mineral and protein contents in developing enamel on maxillary and mandibular incisors of mice with genetically altered expression of enamelin (A, B) and ameloblastin (C, D). Mineral (circles) and protein (squares) weights per 1-mm-long enamel strip $(\mathrm{A}, \mathrm{C})$ and change in weights of both between sequential strips (B, D) for developing enamel on incisors from wild-type $\left(\right.$ Enam ${ }^{+/+}$, $\mathrm{Ambn}^{+/+}$; blue and red symbols), heterozygous $\left(\right.$Enam $^{+/-}, \mathrm{Ambn}^{+/-5,6}$; mauve and green symbols), and null (Enam $\left.{ }^{-/-}\right)$and doublemutant $\left(A m b n^{-5,6 /-5,6}\right)$ mice (yellow and cyan symbols). Each graph represents mean $\pm 95 \%$ CI. The location of the stages of amelogenesis are illustrated by the dashed lines in A (S, secretory stage; M, maturation stage; E, erupted portion) and apply equally to A-D. The enamel from the mandibular incisors of Enam ${ }^{+/-}$mice is soft to allow strips to be cut across the length of the whole tooth (A, B). The incisors in Enam ${ }^{-/-}$null and $\mathrm{Ambn}^{-5,6 /-5,6}$ mutant mice are covered by a thin, disorganized calcified material that is not enamel (A-D). 

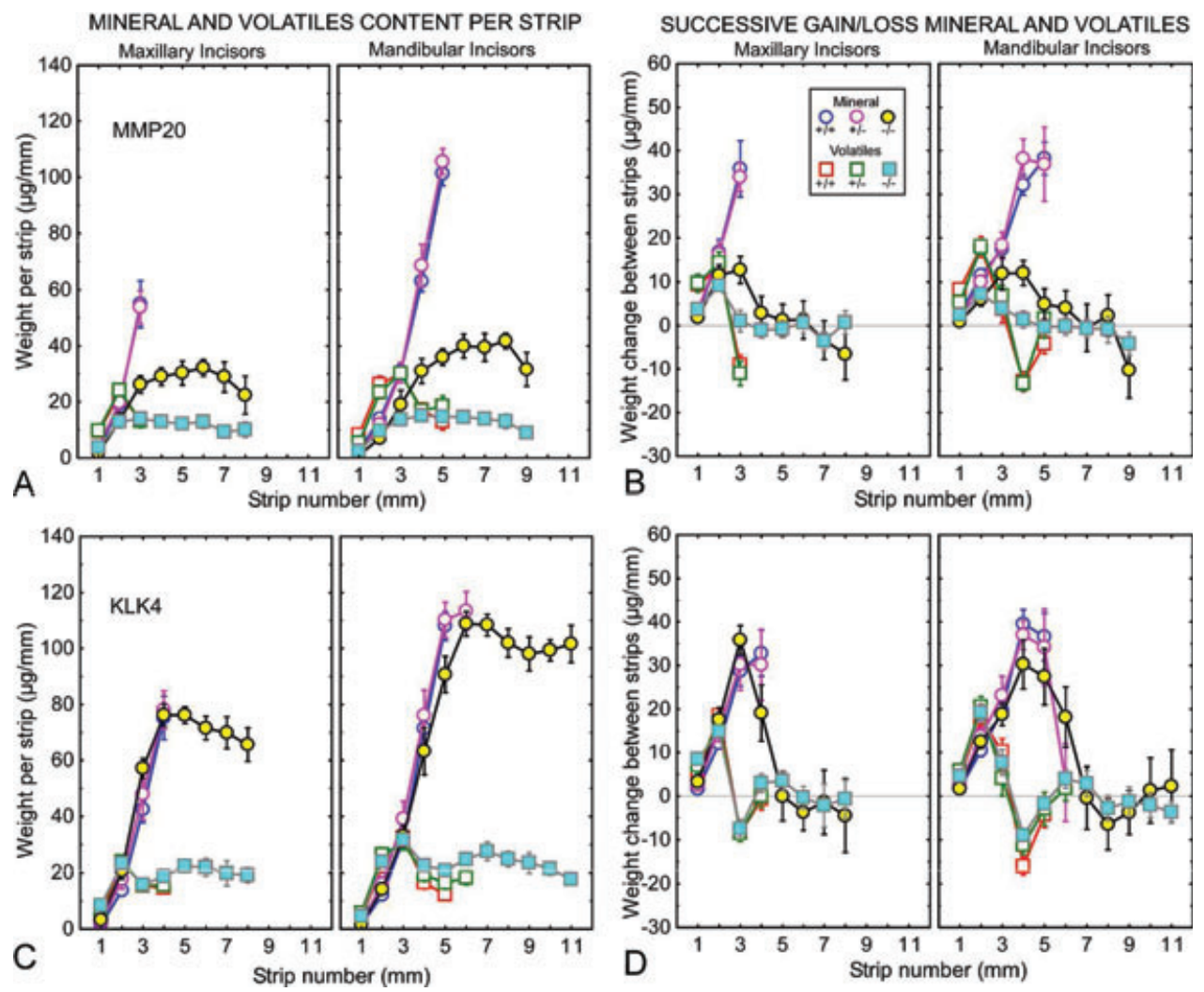

Fig. 3. Mineral and protein contents in developing enamel on maxillary and mandibular incisors of mice with genetically altered expression of matrix metalloproteinase 20 (MMP20) (A, B) and kallikrein-related peptidase 4 (KLK4) (C, D). Mineral (circles) and protein (squares) weights per 1-mm-long enamel strip (A, C) and change in weights of both between sequential strips (B, D) for

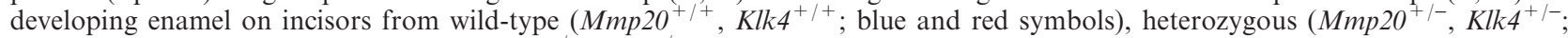

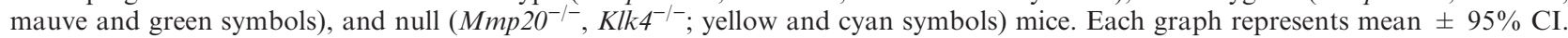
See Fig. 2A for the location of the stages of amelogenesis relative to each graph. The enamel from the mandibular incisors of $\mathrm{Mmp} 2 \mathrm{O}^{-/-}$and $\mathrm{Klk}^{-/-}$mice is soft enough to allow strips to be cut across the length of the whole tooth (A-D). The enamel in $\mathrm{Mmp} 2 \mathrm{O}^{-/-}$mice is thinner than normal and disorganized (A, B), whereas the enamel in $\mathrm{Klk4^{-/ }}$ mice is normal in thickness but softer than normal in depth $(\mathrm{C}, \mathrm{D})$.

mandibular incisors (Figs 2A-D and 3A-D; red and blue symbols; Fig. 4, blue symbols). In two cases on mandibular incisors $\left(\right.$ Enam $\left.^{+/+}, \mathrm{Ambn}^{+/+}\right)$, the volatile contents appeared to increase between strips 4 and 5 along with continued increases in mineral content (Fig. 2A-D; red and blue symbols). Enamel strips containing the most mature enamel that could be hand dissected had volatile contents ranging from 12 to $15 \mu \mathrm{g} \mathrm{mm}^{-1}$ on maxillary incisors and from 12 to $19 \mu \mathrm{g} \mathrm{mm}^{-1}$ on mandibular incisors (Table S2, +/+; Figs 2A,C and 3A,C; red symbols). The mean mineral content in these strips was $61 \mu \mathrm{g} \mathrm{mm}^{-1}$ and $115 \mu \mathrm{g} \mathrm{mm}^{-1}$, respectively, representing $82 \%$ and $89 \%$ mineral by dry weight (Table S2, +/+; Figs $2 \mathrm{~A}, \mathrm{C}$ and $3 \mathrm{~A}, \mathrm{C}$; blue symbols). Hence, maturing enamel on both maxillary and mandibular incisors changed from a soft physical state in early maturation into a hardened state at mid-to-late maturation and showed an increase of approximately 3.5 -fold in mineral content with an overall net loss of only about one-half of its volatile content. The lowest volatile content detected in wild-type mice in the most mature enamel strips was $11.5 \mu \mathrm{g} \mathrm{mm}^{-1}$ on maxillary incisors and $10.8 \mu \mathrm{g} \mathrm{mm}^{-1}$ on mandibular incisors (Table S2).

\section{Mineral and volatile content in enamel on maxillary and mandibular incisors of heterozygous mice}

For the most part, enamel strips removed from the maxillary incisors of mice that had loss of function of one gene for the four proteins of interest $\left(\right.$ Enam $^{+/-}$, $\mathrm{Ambn}^{+/-5,6}, \mathrm{Mmp}_{20^{+/-}}$, or $\mathrm{Klk4^{+/- }}$ ) showed changes in volatile and mineral contents that were almost identical to those described for wild-type mice (Figs 2A-D and 3A-D; green and mauve symbols; Table S2). One exception was $A m b n^{+/-5,6}$ mice, as one extra strip (strip 4) could be dissected from their teeth (Fig. 2C,D). This strip contained a slightly higher content of volatiles than normal, but $82 \%$ mineral by dry weight (Table S2).

Enamel strips removed from the mandibular incisors of heterozygous mice showed no difference $\left(\mathrm{Mmp}_{20} \mathrm{O}^{+-}\right.$), small differences $\left(A m b n^{+/-5,6}\right.$ and $\left.K l k 4^{+/-}\right)$, or a large difference $\left(\right.$ Enam $\left.^{+/-}\right)$in volatile and/or mineral contents compared with wild-type controls (Figs 2A-D and 3A$\mathrm{D}$; green and mauve symbols compared with red and blue symbols; Table S2). Mandibular incisors of Enam ${ }^{+/-}$ mice showed peak amounts of volatiles in early maturation that were $15 \%$ below the normal amounts and associated with mineral contents that were $28 \%$ below 


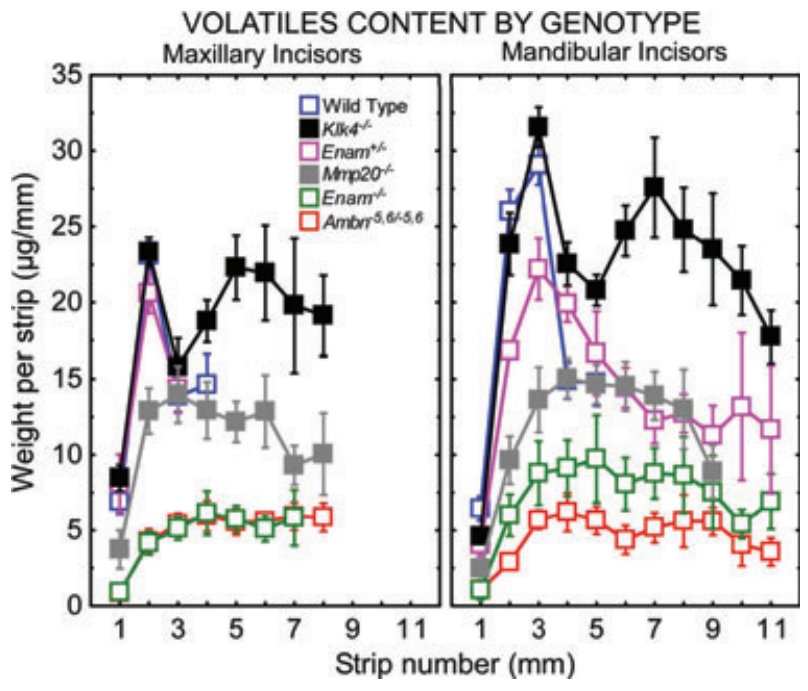

Fig. 4. Comparison of volatile contents in enamel strips obtained from maxillary and mandibular incisors of wild-type, Enam $^{+/-}$, and null/mutant mice. Each graph represents mean $\pm 95 \%$ CI. See Fig. 2A for the location of the stages of amelogenesis relative to each graph. Considerable differences in the distribution of volatiles occurs following partial $\left(\right.$ Enam $\left.^{+/-}\right)$ or total loss of function of the two non-amelogenins $\left(\mathrm{Enam}^{-/}\right.$, $\left.A m b n^{-5,6 /-5,6}\right)$ and the two proteinases $\left({\left.\mathrm{Mmp} 2 \mathrm{O}^{-/-}, \mathrm{Klk}^{-/-}\right)}^{\text {, }}\right.$ required for normal enamel development. Most surprising is the seemingly constant volatile levels throughout the maturation stage in mice lacking matrix metalloproteinase 20 (MMP20) and the secondary rise in volatiles seen during late maturation in mice lacking kallikrein-related peptidase 4 (KLK4).

normal (strip 3; Figs 2A and 4; Table S2). The amount of volatiles dropped by one-half during maturation, as in wild-type mice, but this decrease was spread over six strips (strips 3-9; from 3 to $9 \mathrm{~mm}$ ) rather than over two strips (strips $3-5$; from 3 to $5 \mathrm{~mm}$ ), as seen in wild-type mice (Fig. 2A; Table S2). The mineral content of enamel strips in Enam $^{+/-}$mice increased by only 2.7-fold between strips 3-9 as opposed to wild-type mice, which showed 3.7-fold increases in mineral contents in strips 3-5 (Table S2). The enamel closest to the gingival margin in Enam $^{+/-}$mice contained $84 \%$ mineral by weight as opposed to that in wild-type mice that showed close to $90 \%$ mineral by weight as early as strip 5 (Table S2; Fig. 5).

Enamel strips from the mandibular incisors of $\mathrm{Ambn}^{+/-5,6}$ mice showed a trend to have volatile and mineral contents below normal that became more accentuated and significantly different by strip 5 (Fig. 2C,D). One extra strip (strip 6) could be dissected from these teeth (Fig. 2C,D). This strip contained $21 \%$ less volatiles and $23 \%$ less mineral than normal (Table S2) but it still contained $88 \%$ mineral by dry weight, the same as strip 5 in wild-type mice (located next to very hard enamel) (Fig. 1; Table S2; Fig. 5). Enamel strips from the mandibular incisors of $K l k 4^{+/-}$mice had seemingly normal volatile and mineral contents up to strip 5 , but like $A m b n^{+/-5,6}$ mice, one extra strip (strip 6) could also be dissected from these teeth (Fig. 3C,D). This strip contained $49 \%$ more volatiles and 5\% more mineral than normal (Table S2) and contained $86 \%$ mineral by dry weight (Table S2; Fig. 5).

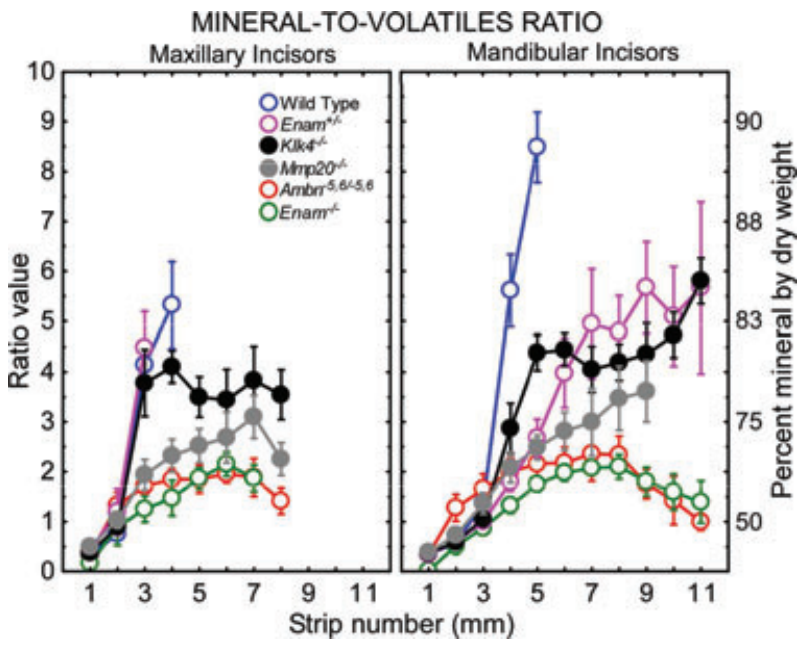

Fig. 5. Comparison of mineral-to-volatiles ratios and per cent mineral by dry weight in enamel strips obtained from maxillary and mandibular incisors of wild-type, Enam ${ }^{+/-}$and null/mutant mice. Each graph represents mean $\pm 95 \%$ CI. See Fig. 2A for the location of the stages of amelogenesis in each graph. Complete loss of function of either one of the non-amelogenins or enamel proteinases drastically lowers the mineral-to-volatiles ratio. In Enam $^{+/-}$mice, the reduction occurs because the enamel contains less total mineral than normal, whereas in $\mathrm{Mmp} 2 \mathrm{O}^{-/-}$and $\mathrm{Klk}^{-/-}$mice the problem is associated with higher than normal volatile contents across the maturation stage. There is no enamel formed in $\mathrm{Enam}^{-/-}$null and $\mathrm{Ambn}^{-5,6 /}$ $-5,6$ mutant mice and the mineral-to-volatiles ratio of material dissected off the dentin of these teeth reflects a composition similar to compact bone (i.e. a ratio of $\sim 2$ and a per cent mineral by weight of approximately $69 \%$ ).

\section{Mineral and volatile content in enamel on maxillary and mandibular incisors of homozygous null/mutant mice}

All $\mathrm{Enam}^{-/-}, \mathrm{Ambn}^{-5,6 /-5,6}, \mathrm{Mmp}^{20^{-/-}}$, and $\mathrm{Klk}^{-/-}$mice showed moderate or major changes in volatile and mineral contents in enamel strips removed from maxillary and mandibular incisors compared with wild-type incisors (Figs 2A-D and 3A-D; cyan and yellow symbols compared with red and blue symbols; Table S2). Enam $^{-1-}$ and $\mathrm{Ambn}^{-5,6 /-5,6}$ mice showed complete shutdown of amelogenesis and development of severely dysplasic enamel organ epithelia, which formed a thin, disorganized, and poorly calcified material containing $63-67 \%$ mineral by weight (Figs $2 \mathrm{~A}-\mathrm{D}$ and $4-6$; Table S2).

The incisors of $\mathrm{Mmp20}^{-/-}$mice were covered by a disorganized enamel that was thinner than normal, under-mineralized, and covered by enamel organ cells that progressed through the usual steps of amelogenesis; however, the ameloblasts were somewhat disorganized and showed a tendency to form mineralized nodules attached to the enamel surface that distorted the epithelial organization, especially at later time-points in maturation (Fig. 6C) (44). Enamel strips from the incisors of $\mathrm{Mmp20^{-/- }}$ mice showed a trend for below-normal volatile contents that peaked in strips that were located $1 \mathrm{~mm}$ more incisal compared with wild-type mice (strip 3 

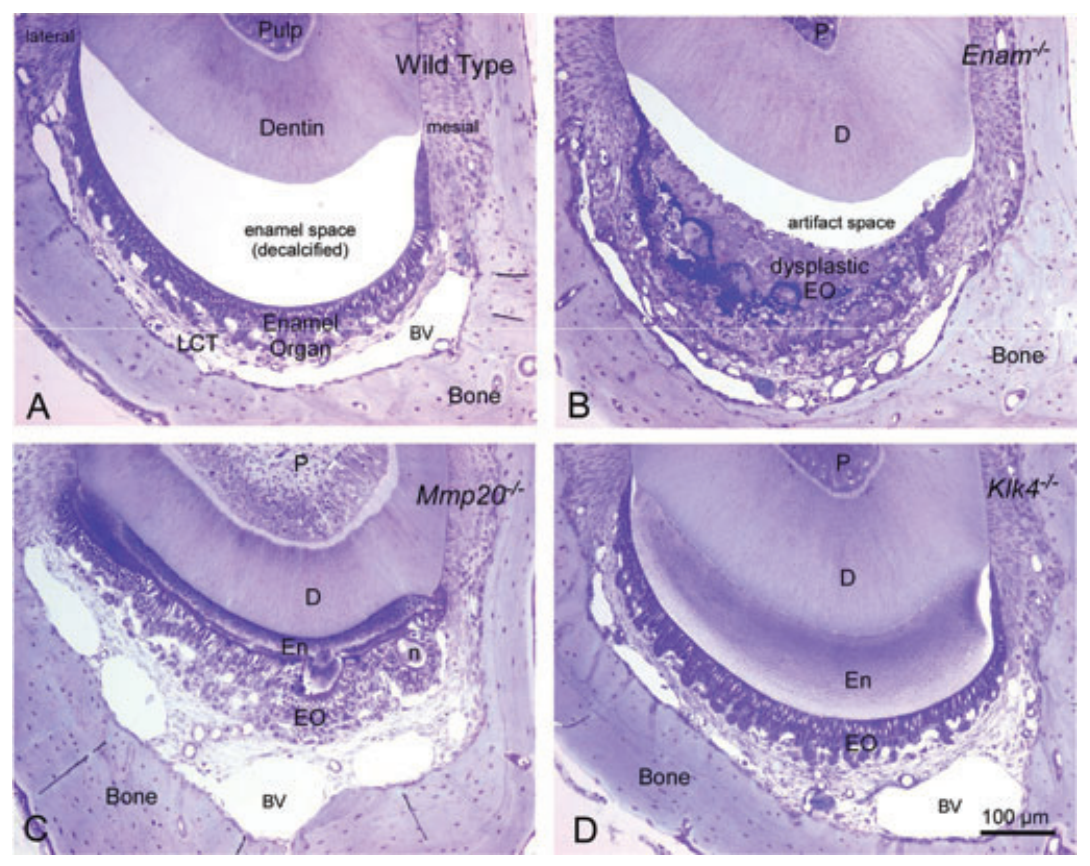

Fig. 6. Transverse (cross) sections of decalcified mandibular incisors from wild-type (A), Enam ${ }^{-/-}$(B), $\mathrm{Mmp}^{20^{-/-}}$(C), and $\mathrm{Klk}^{-/-}$ (D) mice cut in an area of late maturation ( strip 6 or 7). These are 0.5 - $\mu$ m-thick sections of Epon-embedded teeth stained with toluidine blue. The bar in D applies equally to A-D. There is a large empty space in wild-type mice at this level of sectioning as a result of complete dissolution of the enamel by EDTA. Enam ${ }^{-/-}$mice have a thickened and grossly distorted enamel organ (EO) that easily separates off the dentin. Similar dysplasia of the enamel organ and lack of an enamel layer is also seen in $A m b n^{-5,6 /-5,6}$ mice (not shown). The enamel in $\mathrm{Mmp20}^{-/-}$mice is thinner than normal and disorganized, and shows surface nodules (n) attached to an outer layer of hyaline material lacking any rod structure. Enamel organ cells maintain continuity by arranging themselves around the surface of the nodules. The enamel and enamel organ cells in $\mathrm{Klk}^{-/-}$mice appear normal but the enamel itself retains considerable organic material (bluish/purple staining) especially in deeper regions of the enamel layer near the dentin (D). BV, blood vessel; D, dentin; EO, enamel organ; En, enamel; n, nodule of enamel; P, pulp.

on maxilla and strip 4 on mandible; Figs $3 \mathrm{~A}, \mathrm{~B}$ and 4 ; Table S2). The amounts of volatiles found in these peaks were half of that found in wild-type mice but they contained the same (mandible) or higher (maxilla) levels of mineral compared with volatile peaks seen in wildtype mice (Figs 3A,B and 4; Table S2). The amount of volatiles in enamel strips did not change significantly thereafter across the rest of the maturation stage to the gingival margin of the incisor (Figs 3A,B and 4; Table $\mathrm{S} 2$ ). The mineral content in these enamel strips increased by about $30 \%$, reaching a level of $74 \%$ mineral by weight (average for maxilla and mandible; Figs $3 \mathrm{~A}, \mathrm{~B}$ and 5; Table S2). The enamel strips obtained from near the erupted area contained $41 \%$ less total mineral on maxillary incisors and $59 \%$ less total mineral on mandibular incisors compared with strips 3 (maxilla) and 5 (mandible) in wild-type mice (Figs 3A,B and 5; Table S2).

Enamel strips from the incisors of $\mathrm{Klk}^{-/-}$mice showed normal volatile and mineral contents up to early maturation (to strip 2 on maxilla and to strip 3 on mandible; Fig. 3C,D; Table S2). The volatile contents thereafter declined sharply for 1 (maxilla) or 2 (mandible) strips with accompanying large increases in mineral contents similar to trends seen in wild-type mice (Figs 3C,D and 4, 5). The decrease in volatile contents was not as large, however, as those seen in wild-type mice, and the enamel strips at this time contained more volatiles but about the same quantity of mineral as the equivalent strips in wild-type mice (Figs 3C,D and 4). The amount of volatiles in enamel strips rose again, creating a second peak located $2 \mathrm{~mm}$ from the gingival margin (strip 5 on maxilla and strip 7 on mandible; Fig. 4). The amount of volatiles in enamel strips then declined progressively towards the gingival margin and out onto the erupted portion of the tooth (Figs 3C,D and 4). From a point just prior to the second peak in volatiles up to the gingival margin, the amount of mineral in enamel strips seemed to decrease (Figs 4 and 5). The enamel strip with the highest mineral content (strip 3 on maxilla and strip 6 on mandible) contained the same amount of total mineral as enamel from wild-type mouse but twice as much protein, resulting in a $10 \%$ softer strip with $80 \%$ mineral by weight and a much reduced mineral-to-volatiles ratio (Figs 3C,D and 4, 5).

\section{Discussion}

The results from this study provide a good demonstration of the dependence of amelogenesis on the expression and secretion of both non-amelogenins (enamelin and ameloblastin) during the secretory stage as well as of two proteinases in sequential order: MMP20 during the secretory stage followed by KLK4 during the maturation stage. There is also little doubt from the findings of this study that enamel organ cells, especially ameloblasts, are 
in direct and constant 'communication' with the extracellular enamel layer they are producing. They appear to be able to detect not only the types of proteins present extracellularly but also their amounts, as revealed by the effects seen, for example, on mandibular incisors arising from the loss of function of one gene for enamelin $\left(\right.$ Enam $\left.^{+/-}\right)$causing alterations in the amount of mineralization, or the loss of both genes $\left(\right.$ Enam $\left.^{-/-}\right)$resulting in complete shutdown of amelogenesis. One major limitation of amelogenesis is that each non-amelogenin and each proteinase cannot compensate for the other (in other words, there is no built-in redundancy). Another weakness is that enamel organ epithelial cells do not seem to have many alternative tools available to draw upon when protein production goes faulty. Consequently, the end product of any alteration or deviation from normal, including certain critical point mutations in some of the enamel-associated proteins (45), is the formation of undermineralized, poor-quality enamel (Fig. 5). It is then a case of the level to which mineralization fails (to 80,70 , or $60 \%$ mineral by dry weight; Fig. 5).

One challenge inherent to this study is trying to ascertain with reasonable confidence to what extent 'volatiles' represent 'protein' in freeze-dried strips of forming, maturing, nearly mature, and mature enamel following ashing. This is an important question because in this study volatiles were always detected, regardless of the maturity level of the mineral phase in an enamel strip. Volatiles were also found in amounts that were often higher than expected, especially in more mature enamel. The data in Fig. S1 clearly imply that for the secretory stage and the maturation stage, the volatile contents in up to the second-last strip that can be cut by hand without damaging a scalpel blade (strip 4 on mandibular mouse incisors) are synonymous with the amounts of protein that are present in enamel strips. The most mature enamel strip that can be removed manually from normal mouse incisors (strip 5 or strip 6 on the mandible), however, seems to contain more than just protein, although what this might be is undefined at present (Fig. S1, strip 11 for rat incisors = strip 5.5 in mouse; $17.9 \pm 4.7 \mu \mathrm{g} \mathrm{mm}^{-1}$ of total volatiles with an average of $7.9 \pm 2.0 \mu \mathrm{g} \mathrm{mm}^{-1}$ estimated protein content $=$ only $44 \%$ of volatiles as protein). Based on long-standing ideas of the removal of proteins from intercrystalline spaces and their replacement by enamel fluids, followed by removal of the fluids to allow crystal growth in width and breadth $(2,3)$, we conclude that the 'extra' volatile component in an almost mature enamel strip could represent crystal-bound water. This may cause the increase in volatile contents seen, for example, on mandibular mouse incisors between strip 4 and strip 5, and sometimes strip 6, in Enam ${ }^{+/+}$(Fig. 2B), $\mathrm{Ambn}^{+/+}$and $\mathrm{Ambn}^{+/-}$(Fig. 2D), $\mathrm{Mmp}^{+0^{+/+}}$and

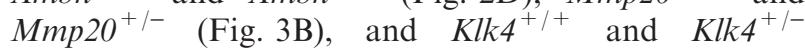
(Fig. 3D) mice. Based on the results from ashing various forms of mineral shown in Table S1, we further conclude that the amount of crystal-bound water probably decreases as enamel crystallite sizes increase with maturity (42).
Another difficult challenge in this study is trying to decide, in cases of altered amelogenesis, where strips with softer-than-normal enamel can be cut from incisors beyond strip position 5 or 6 , if the volatile contents in these strips represent mostly protein, varying amounts of protein and crystal-bound water, or bound water alone. These possibilities cannot be selected with any degree of confidence based solely on the results of this study, but the findings from other studies examining the appearance of crystals in areas of enamel that are softer compared with normal enamel suggest that enamel crystal sizes can be smaller than normal and proteins can be a major component in these types of defects $(3,5,39,46,47)$. Hence, in cases such as mandibular incisors of $\mathrm{Enam}^{+/}$, $\mathrm{Mmp} 2 \mathrm{O}^{-/-}$, and $\mathrm{Klk}^{-/-}$mice, where enamel strips can be removed all the way to the gingival margin and out onto the erupted portion of the tooth, the elevated levels of volatiles detected in these strips probably represent higher than normal amounts of proteins/fragments retained in these strips (delayed maturation) in addition to some crystal-bound water normally associated with the mineral phase at a particular mineral-to-volatiles ratio.

Among the perplexing results in this study were the findings of complete shutdown of amelogenesis in mice lacking enamelin $\left(\mathrm{Enam}^{-/-}\right)$or expressing both copies of a mutated ameloblastin protein $\left(A m b n^{-5,6 /-5,6}\right)$ (Fig. 2). As discussed previously $(34,41)$, there is currently no clear explanation, based on the primary structure of these proteins, for why enamel organ cells are unable to initiate the appositional growth phase of amelogenesis or why the cells become dysplastic. Another problematic result with no explanation is why mandibular incisors of Enam $^{+/-}$mice show such a strong heterozygous effect of poor mineralization, whereas the maxillary incisors appear normal in terms of mineral and volatile contents of their forming enamel (Fig. 2C,D; Table S2) (34). It is certainly possible and even likely that the overall rate at which appositional growth of enamel occurs varies somewhat at different locations across the crown of the same tooth as well as between different teeth, but it is hard to conceive of enamel formation being different on the same or different teeth in terms of the amounts of enamelin needing to be exported by ameloblasts per unit volume of new enamel being formed per unit time during the secretory stage (in other words, there is probably a basic quantity of amelogenin, enamelin, and ameloblastin that ameloblasts must release to make enamel, regardless of tooth type). This suggests that there are other factors at play on the mandibular incisors of Enam $^{+/-}$mice that remain to be identified. For example, Table S2 indicates that at early maturation the amount of volatiles and mineral in enamel strips from these mice are both about $20 \%$ below normal, whereas later in maturation the enamel strips have a volatile content that is about $30 \%$ below normal and a mineral content that is $50 \%$ below normal. In other words, these mice do not have soft enamel because too much protein/fragments are retained but because there is too little mineral. Although it is possible that some of the protein/fragments present in the forming enamel of these mice may be especially efficient at inhibiting mineralization and 
crystal growth, we suspect that the main problem on the mandibular incisors of Enam ${ }^{+/-}$mice is related to lower capacity for mineral ion transport than an inability to remove protein/fragments.

Completely the opposite problem occurs in Mmp20 and Klk4 null mice. Although displaced incisally by $1 \mathrm{~mm}$ on mandibular incisors, early maturation-stage enamel on the mandibular incisors of $\mathrm{Mmp} 20$ null mice in absolute terms appears to contain $50 \%$ of the normal amount of volatiles and a normal amount of mineral compared with wild-type mice (Figs $3 \mathrm{~A}, \mathrm{~B}$ and 4, 5; Table S2; strip 4 rather than strip 3). The enamel layer in these mice, however, is much thinner than normal (Fig. 6C); hence, in relative terms, if we normalize for differences in thickness, the enamel at this time-point in Mmp20 null mice has slightly more volatiles than normal and more than twice as much mineral as normal (Table $\mathrm{S} 2$; divide the MMP20 values shown by 0.4 ). In more mature areas near the gingival margin (strip 8), the enamel in Mmp20 null mice in both absolute and relative terms contains nearly the same amount of volatiles but has $35 \%$ more mineral compared with early-maturation enamel. The weight of mineral in this more mature strip (strip 8 vs. 4) if normalized to enamel thickness actually contains very close to the same amounts of mineral observed in wild-type and heterozygous mice (41.8/ $\left.0.4=104.5 \mu \mathrm{g} \mathrm{mm}^{-1}\right)$. Hence, although there appears to be no net protein loss across the maturation stage in Mmp20 null mice, the poorly organized and thin enamel in these animals seems to acquire additional new mineral, as occurs in mice creating normal enamel.

A variation of this same pattern is seen in Klk4 null mice. In this case, the site for the peak in volatiles in early maturation occurs in the normal strip 3 position, and the absolute amounts of volatiles and mineral in the strip at this time are also normal (Figs 3C,D and 4, 5; Table S2). In a more mature location (strip 6), the amount of volatiles appears to drop by only $22 \%$, resulting in twofold higher levels of volatiles in the strip compared with wild-type mice (Figs 3C,D and 4; Table S2). This is also an area of the incisor in Klk4 null mice where volatile contents of strips increase then decrease with length, giving the overall impression, as in Mmp20 null mice, that volatiles are not being lost when in the case of Klk4 null mice they are, once from early maturation to midmaturation and again in late maturation and out onto the erupted portion of the tooth (Figs 3C,D and 4; Table S2). As noted elsewhere (35), the factor(s) that causes the increase of volatiles in late maturation in the Klk4 null mice is not at all clear at the present time. The possibilities include some factor related to the release of the ferritin-base iron pigment that occurs almost exactly in line with the location of the peak of volatiles at strip position 7 by analogy to what is seen in rat incisors (35, 48 ), or perhaps to increases in the amount of crystalbound water, or both. Interestingly, the amount of mineral contained in strip 6 at midmaturation in Klk4 null mice is 3.3 -fold higher than at strip 3 , similarly to wild-type mice, and the absolute weight of mineral present at this time is similar to the amount observed in wild-type mice (Table $\mathrm{S} 2$ ). We are unsure at this time if the apparent drop in total weight of mineral from strips 5 to 8 on maxillary incisors and from strips 6 to 9 on mandibular incisors of Klk4 null mice represents a real loss of mineral content. This uncertainty arises because deviations for measurements in these areas are high (Fig. 3C) and, as a result, the means between these strips are not significantly different except at the extremes.

One of the most critical events in enamel maturation seems to be during early and midmaturation where the volatile content in enamel drops sharply and the mineral content rises dramatically in an inverse relationship over a distance of only 1-2 mm of tooth length (Figs 2 and 3). In one case where the rapid decline in volatiles was not as large as that which occurs in wild-type mice $\left(\mathrm{Klk}^{-/-}\right)$, the rise in mineral content was below normal (Fig. 3 C,D). In two cases where the decline in volatiles was substantially less than normal and spread out over a longer length of time across the maturation stage $\left(\right.$ Enam $^{+/-} ; \mathrm{Mmp}^{20^{-/-}}$), the rate of increase in mineral content in unit samples of enamel was also substantially delayed (Figs 2A,B and 3A,B). In several, but not all, cases where a rise in volatiles occurred after the volatiles content was low (e.g. the mandibular incisors of Enam $^{+/+}, \mathrm{Ambn}^{+/-5,6}, \mathrm{Mmp}_{20} \mathrm{O}^{+/-}, \mathrm{Klk}^{+/-}$, and $K l k 4^{-/-}$mice), the amount of mineral gained between the strip with the lower volatile content and the next adjacent one with a higher volatile content declined correspondingly (Figs 2 and 3). These findings provide considerable direct support to the idea that the removal of proteins/fragments is critical to allow crystallites to undergo maturational volumetric expansion, but it is equally clear from these data that proteins/fragments seem to exert more of an effect in vivo on the rate of crystallite growth as opposed to preventing growth from happening at all.

Altogether, the results of this study suggest that maturational growth of enamel crystals can occur in the presence of relatively large amounts of proteins and/or their fragments. The crown problems associated with $\mathrm{Enam}^{-/-}$and $\mathrm{Ambn}^{-5,6 /-5,6}$ mice have nothing to do with protein or mineral but they occur because amelogenesis shuts down early and the enamel organ cells transform into a dysplastic epithelia that secrete a thin calcified material that is not enamel. The soft, chalky enamel on the mandibular incisors of Enam ${ }^{+/-}$mice forms not as a consequence of containing too much organic material but because it lacks sufficient amounts of mineral potentially arising from some as-yet-undefined problem with mineral ion transport during the maturation stage. $\mathrm{Mmp20^{-/- }}$ and $\mathrm{Klk}^{-1-}$ mice have softer-than-normal enamel, not because there is too little mineral in the enamel layer but because the enamel layer in both cases contains roughly twice as much organic material as it should at later times in maturation. This extra organic material does not add much to the total gross weight of a unit sample of enamel but it does drastically lower the mineral-to-volatiles ratio in the sample and seems to interfere with the ability of enamel crystallites to interlock, the final step in amelogenesis that makes enamel very hard (4), but it does not prevent the crystallites 
from undergoing volumetric expansion in width and breadth.

Acknowledgements - The authors gratefully acknowledge help by Rima Wazen from the Université de Montréal in providing frozen jaws from $A m b n^{-e x 5,6}$ mutant mice (all genotypes), and Jeannie Mui from FEMR of McGill University for preparing and staining plastic sections from wild-type, Enam, Mmp20, and Klk4 null samples. This research was supported by USPHS Research Grants DE011301 (Enam null), DE016276 (Mmp20 null), and DE019775 (Klk4 null) from the National Institute of Dental and Craniofacial Research, National Institutes of Health and by the CIHR ( $A m b n^{-\mathrm{ex} 5,6}$ mutant).

Conflicts of interest - All authors declare that there are no competing interests.

\section{References}

1. Margolis HC, Beniash E, Fowler CE. Role of macromolecular assembly of enamel matrix proteins in enamel formation. $J$ Dent Res 2006; 85: 775-793.

2. Robinson C, Kirkham J, Brookes SJ, Bonass WA, Shore RC. The chemistry of enamel development. Int J Dev Biol 1995; 39: $145-152$

3. Robinson C, Brookes SJ, Bonass WA, Shore RC, Kirkham J. Enamel maturation. Chiba Found Symp 1997; 205: 156-170; discussion $150-154$

4. Sмітн CE. Cellular and chemical events during enamel maturation. Crit Rev Oral Biol Med 1998; 9: 128-161.

5. Wright JT, Hall K, Yamauchi M. The protein composition of normal and developmentally defective enamel. Chiba Found Symp 1997; 205: 85-99; discussion 99-106.

6. NANCI A. Ten cate's oral histology: development, structure, and function, 7th edn. St. Louis, MO: Mosby Elsevier, 2008; 411.

7. WeINER S. Organization of extracellularly mineralized tissues: a comparative study of biological crystal growth. CRC Crit Rev Biochem 1986; 20: 365-408.

8. Moradian-Oldak J, Goldberg M. Amelogenin supra-molecular assembly in vitro compared with the architecture of the forming enamel matrix. Cells Tissues Organs 2005; 181: 202208.

9. Yang X, Wang L, Qin Y, Sun Z, Henneman ZJ, MoradianOldak J, Nancollas GH. How amelogenin orchestrates the organization of hierarchical elongated microstructures of apatite. J Phys Chem B 2010; 114: 2293-2300.

10. Sмith CE, NAnCi A. Protein dynamics of amelogenesis. Anat Rec 1996; 245: 186-207.

11. Nanci A, Warshawsky H. Characterization of putative secretory sites on ameloblasts of the rat incisor. Am J Anat 1984; 171: 163-189

12. Ryu OH, Fincham AG, Hu JC, Zhang C, Qian Q, Bartlett JD, Simmer JP. Characterization of recombinant pig enamelysin activity and cleavage of recombinant pig and mouse amelogenins. J Dent Res 1999; 78: 743-750.

13. Ryu OH, Hu JC, Yamakoshi Y, Villemain JL, Cao XH, Zhang CH, Bartlett JD, Simmer JP. Porcine kallikrein-4 activation, glycosylation, activity, and expression in prokaryotic and eukaryotic hosts. Eur J Oral Sci 2002; 110: 358-365.

14. Begue-Kirn C, Krebsbach PH, Bartlett JD, Butler WT. Dentin sialoprotein, dentin phosphoprotein, enamelysin and ameloblastin: tooth-specific molecules that are distinctively expressed during murine dental differentiation. Eur J Oral Sci 1998; 106: 963-970.

15. Hu JC, Sun X, Zhang C, Liu S, Bartlett JD, Simmer JP. Enamelysin and kallikrein-4 mRNA expression in developing mouse molars. Eur J Oral Sci 2002; 110: 307-315.

16. Robinson C, Brookes SJ, Shore RC, Kirkham J. The developing enamel matrix: nature and function. Eur J Oral Sci 1998; 106: $282-291$.
17. Hu JC, Yамakoshi Y. Enamelin and autosomal-dominant amelogenesis imperfecta. Crit Rev Oral Biol Med 2003; 14: 387398.

18. Usкокоvic V, Kim MK, Li W, Habelitz S. Enzymatic processing of amelogenin during continuous crystallization of apatite. J Mater Res 2008; 23: 3184-3195.

19. Hu JC, Zhang CH, Sun XL, Yang Y, CaO XH, Ryu O, SIMMER JP. Characterization of the mouse and human PRSS17 genes, their relationship to other serine proteases, and the expression of PRSS17 in developing mouse incisors. Gene 2000; 251: $1-8$.

20. Simmer JP, Sun X, Yamada Y, Zhang CH, Bartlett JD, Hu JC. Enamelysin and kallikrein-4 expression in the mouse incisor. In: KOBAYASHI I, OZAWA H, ed. Biomineralization: formation, diversity, evolution and application; Proceedings of the 8th international symposium on biomineralization. Hadano, Japan: Tokai University Press, 2004; 348-352.

21. Simmer JP, Hu Y, Richardson AS, Bartlett JD, Hu JC. Why does enamel in Klk4 null mice break above the dentinoenamel junction? Cells Tissues Organs 2011;194: 211-215.

22. Lu Y, Papagerakis P, Yamakoshi Y, Hu JC, Bartlett JD, SIMMER JP. Functions of KLK4 and MMP-20 in dental enamel formation. Biol Chem 2008; 389: 695-700.

23. Nanci A, Slavkin HC, Smith CE. Application of high-resolution immunocytochemistry to the study of the secretory, resorptive, and degradative functions of ameloblasts. Adv Dent Res 1987; 1: 148-161.

24. Nanci A, Slavkin HC, Smith CE. Immunocytochemical and radioautographic evidence for secretion and intracellular degradation of enamel proteins by ameloblasts during the maturation stage of amelogenesis in rat incisors. Anat Rec 1987; 217: $107-123$.

25. Smith Ce, Pompura JR, Borenstein S, Fazel A, Nanci A. Degradation and loss of matrix proteins from developing enamel. Anat Rec 1989; 224: 292-316.

26. Sмiтн CE. Ameloblasts, secretory and resorptive functions. J Dent Res 1979; 58: 695-706.

27. Kallendach E. Fine structure of rat incisor ameloblasts during enamel maturation. J Ultrastruct Res 1968; 22: 90-119.

28. Reith EJ, Cotty VF. The absorptive activity of ameloblasts during the maturation of enamel. Anat Rec 1967; 157: 577-588.

29. TAKANO Y, OZAWA H. Ultrastructural and cytochemical observations on the alternating morphologic changes of the ameloblasts at the stage of enamel maturation. Arch Histol Jpn 1980; 43: 385-399.

30. SASAKI T. Endocytotic pathways at the ruffled borders of rat maturation ameloblasts. Histochemistry 1984; 80: 263-268.

31. Salama AH, Bailey RL, Eisenmann DR, Zaki AE. Quantitative cytochemistry of lysosomal structures in rat incisor maturation enamel organ. Arch Oral Biol 1990; 35: 535-539.

32. Kallenbach E. Access of horseradish peroxidase (HRP) to the extracellular spaces of the maturation zone of the rat incisor enamel organ. Tissue Cell 1980; 12: 165-174.

33. Porto im, Merzel J, De Sousa FB, Bachmann L, Cury JA, Line SR, GERLACH RF. Enamel mineralization in the absence of maturation stage ameloblasts. Arch Oral Biol 2009; 54: 313321.

34. Smith Ce, Wazen R, Hu Y, Zalzal SF, Nanci A, Simmer JP, $\mathrm{Hu}$ JC. Consequences for enamel development and mineralization resulting from loss of function of ameloblastin or enamelin. Eur J Cell Biol 2009; 117: 485-497.

35. Smith CE, Richardson AS, Hu Y, Bartlett JD, Hu JC, SIMMER JP. Effect of kallikrein 4 loss on enamel mineralization: comparison with mice lacking matrix metalloproteinase 20 . J Biol Chem 2011; 286: 18149-18160.

36. Hu JC, Hu Y, Smith CE, McKee MD, Wright JT, Yamakoshi Y, Papagerakis P, Hunter GK, Feng JQ, YAMAKoshi F, Simmer JP. Enamel defects and ameloblastspecific expression in Enam knock-out/lac $Z$ knock-in mice. J Biol Chem 2008; 283: 10858-10871.

37. Fukumoto S, Kiba T, Hall B, Iehara N, Nakamura T, Longenecker G, Krebsbach PH, Nanci A, Kulkarni AB, YAMADA Y. Ameloblastin is a cell adhesion molecule required 
for maintaining the differentiation state of ameloblasts. $J$ Cell Biol 2004; 167: 973-983.

38. Caterina JJ, Skobe Z, Shi J, Ding Yl, Simmer JP, BirkedalHANSEN H, BARTLETT JD. Enamelysin (matrix metalloproteinase 20)-deficient mice display an amelogenesis imperfecta phenotype. J Biol Chem 2002; 277: 49598-49604.

39. Simmer JP, Hu Y, Lertlam R, Yamakoshi Y, Hu JC. Hypomaturation enamel defects in Klk4 knockout/lacZ knockin mice. J Biol Chem 2009; 284: 19110-19121.

40. Yamakoshi Y, Richardson AS, Nunez SM, Yamakoshi F, Yamakoshi Y, Milkovich RN, Hu JC, Bartlett JD, Simmer JP. Enamel proteins and proteases in Mmp20 and Klk4 null and double null mice. Eur J Oral Sci 2011; 119 (Suppl. 1): 206216.

41. WaZen RM, Moffatt P, Zalzal SF, Yamada Y, Nanci A. A mouse model expressing a truncated form of ameloblastin exhibits dental and junctional epithelium defects. Matrix Biol 2009; 28: 292-303.

42. Elliott JC. Structure and chemistry of the apatites and other calcium orthophosphates. Amsterdam, The Netherlands: Elsevier, 1994.

43. Shimoda S, Aoba T, Moreno EC. Changes in acid-phosphate content in enamel mineral during porcine amelogenesis. J Dent Res 1991; 70: 1516-1523.

44. Bartlett JD, Skobe Z, Nanci A, Smith CE. Matrix metalloproteinase 20 promotes a smooth enamel surface, a strong dentino-enamel junction, and a decussating enamel rod pattern. Eur J Oral Sci 2011; 119 (Suppl. 1): 199-205.

45. Wright JT, Hart TC, Hart PS, Simmons D, Suggs C, Daley B, Simmer JP, Hu JC, Bartlett JD, Li Y, Yuan ZA, Seow WK, Gibson CW. Human and mouse enamel phenotypes resulting from mutation or altered expression of $A M E L$, ENAM, MMP20 and KLK4. Cells Tissues Organs 2009; 189: 224-229.
46. Robinson C, Kirkham J, Stonehouse NJ, Shore RC. Control of crystal growth during enamel maturation. Connect Tissue Res 1989; 22: 139-145.

47. Wright JT, Deaton TG, Hall Ki, Yamauchi M. The mineral and protein content of enamel in amelogenesis imperfecta. Connect Tissue Res 1995; 32: 247-252.

48. Karim AC, WarshawsKY H. A radioautographic study of the incorporation of iron 55 by the ameloblasts in the zone of maturation of rat incisors. Am J Anat 1984; 169: 327-335.

\section{Supporting Information}

Additional Supporting Information may be found in the online version of this article:

Table S1. Percent change in weight following heating of various mineral samples at $575^{\circ} \mathrm{C}$.

Table S2. Summary information about volatile and mineral content in specific enamel strips.

Fig. S1. Comparison of estimates of protein content in enamel strips vs. amount of volatiles in enamel strips at the same location on the incisor.

Data S1. Materials and methods.

Please note: Wiley-Blackwell are not responsible for the content or functionality of any supporting materials supplied by the authors. Any queries (other than missing material) should be directed to the corresponding author for the article. 